\title{
В.П. Новикова
}

\section{ПЕРЕОСМЫСЛЕНИЕ УНИВЕРСИТЕТА ЧЕРЕЗ ПРИЗМУ МЕТАФОРЫ}

\begin{abstract}
Статья посвящена изучению метафорических моделей смыслообразования, участвуюших в выражении авторского представления о современном университете. В качестве материала использованы англоязычные работы исследователей высшего образования последнего десятилетия. С одной стороны, метафоры служат отражением того, как ученые видят исследовательский университет в контексте современной жизни общества; с другой стороны, с помощью метафор формируются стереотипы восприятия университета у читателей. С помощью метафор переосмысливается и оиенивается роль университета в обществе, высвечиваются проблемные зоны, намечаются дальнейшие перспективы развития.

Ключевые слова: когнитивная лингвистика, языковая метафора, метафорическая модель, высшее образование, исследовательский университет.
\end{abstract}

Современный мир созрел для нового тектонического сдвига в понимании университета как учреждения.

Капил Сибал

Университет наряду с церковью и государством стал одним из важнейших институтов, созданных человеческой цивилизацией и выдержавших испытание временем. Исследовательский университет современного типа (именно об этом типе университета пойдет речь в этой статье) появился всего лишь в начале XIX в., и этот термин может быть впервые применим к реформированному Вильгельмом Гумбольдтом Берлинскому университету [1]. В наши дни исследовательские университеты занимают центральное место в глобальной экономике знаний XXI в. и выступают в роли «флагманов» развития высшего образования по всему миру. Ключевыми для XXI в. реалиями высшего образования по всему миру становятся следующие факторы: массификация образования; роль частного сектора и приватизация государственных учебных заведений высшего образования; бурное развитие азиатских стран как научных центров; экономический кризис и его влияние на высшее образование [2. С. 11]. Несмотря на существующие вызовы, надежды на лучшее будущее связаны во многих странах именно с развитием передовых инновационных университетов, ориентированных на то, чтобы быть на переднем крае проведения научных исследований, имеющих важное значение не только для отдельно взятого города, страны, но и человечества в целом. Осознавая столь важную миссию этого общественного института, большое количество ученых пытается переосмыслить роль университета в современном обществе, дать оценку его деятельности, указать пути и сценарии дальнейшего развития. Данная проблема является, безусловно, концептуально сложной и не может обсуждаться без помощи такого явления в мышлении и 
языке, как метафора. Таким образом, объектом исследования в данной статье стали языковые средства реализации метафоры, которые используют ведущие специалисты современности в области образования и социальных наук в работах, посвященных университетам. Ведущие когнитивные метафорические модели, служащие отражением того, как переосмысливается учёными устоявшийся феномен университета в контексте современной жизни общества, послужили предметом исследования. Изучение метафор помогло наглядно показать ту роль, которую играет университет в современном обществе, высветить проблемные зоны и наметить перспективы развития.

Ортега-и-Гассет, знаменитый испанский философ и социолог, объясняет необходимость использования метафоры для процесса познания следующим образом: «...не все объекты легко доступны для нашего мышления, не обо всем мы можем составить отдельное, ясное и четкое представление. Наш дух вынужден поэтому обращаться к легко доступным объектам, чтобы, приняв их за отправную точку, составить себе понятие об объектах сложных и трудно уловимых. Именно эта магическая сила метафоры и остается тайной: «...метафора, давая некоторое буквальное утверждение, заставляет нас увидеть один объект как бы в свете другого, что влечет за собой прозрение» [3. С. 73].

Изучением понятия метафоры занимались и занимаются многие отечественные и зарубежные лингвисты. В XIX в. Ницше, изучавший метафору как философ и филолог, провозгласил необходимость раскрытия роли метафоры в мыслительной деятельности. Из рассуждений Ницше метафору следует рассматривать не только как частичку процесса обучения, но как базис всего знания, всех когнитивных процессов [6. С. 5]. Разные версии и рефлексы такого подхода к роли метафоры в познании встречаются во всех философских концепциях, которые отмечены печатью субъективизма, антропоцентричности, интуитивизма, интереса к мифопоэтическому мышлению и национальным картинам мира [6]. Одним из направлений когнитивистики (комплекс наук, изучающий ментальные аспекты человеческой деятельности: познание мира, усвоение, хранение и переработка информации, классификация, категоризация и оценка действительности) является когнитивная лингвистика, «в центре внимания которой находится язык как общий когнитивный механизм» [5. С. 54]. Центральное место в когнитивной лингвистике занимает проблема категоризации окружающей действительности, важную роль в которой играет метафора как проявление аналоговых возможностей человеческого разума. Метафору в современной когнитивистике принято определять как ментальную операцию, как способ познания, категоризации, концептуализации, оценки и объяснения мироустройства.

В основе когнитивной метафоры лежит идея о том, что метафора - это феномен не лингвистический, а ментальный: языковой уровень лишь отражает мыслительные процессы. Метафоры в языке - это не украшение мыслей, а лишь поверхностное отражение концептуальных метафор, заложенных в понятийной системе человека и структурирующих его восприятие, мышление и деятельность.

Хосе Ортега-и-Гассет обращает внимание на способность метафоры совмещать абстрактное и конкретное и синтезировать такого рода сведения в 
новые концепты. Поэтому метафора может рассматриваться как механизм, который приводит во взаимодействие познавательные процессы, эмпирический опыт, культурное достояние коллектива, его языковую компетенцию. Цель механизма-метафоры - отобразить в языковой форме чувственно не воспринимаемые объекты и сделать наглядной невидимую картину мира создать ее языковую картину, воспринимаемую за счет вербально-образных ассоциаций составляющих ее слов и выражений [3-4].

Наиболее четко концептуальная теория метафоры сформулирована у Дж. Лакоффа и М. Джонсона. Они описали концептуальную метафору как пересечение знаний одной концептуальной области в другой концептуальной области [6]. Классическое определение метафоры в свете когнитивистской теории дает Стивен Харнард: «...метафора - это когнитивный механизм, посредством которого непрерывные, аналоговые и сенсорно-обоснованные восприятия, которые уже прошли процесс категоризации (символообразования), подвергаются переоценке в новых концептуальных контекстах» [7].

Для того чтобы рассмотреть, каким образом переосмысливается идея университета через призму метафор, целесообразно воспользоваться когнитивной теорией метафорического моделирования, предложенной Дж. Лакоффом и М. Джонсоном, и разработанной на ее основе концепцией А.П. Чудинова [8]. Для описания метафорических моделей необходимо охарактеризовать следующие компоненты модели: исходную понятийную область, понятийную сферу, цель метафорической экспансии, базовый концепт - элемент, служащий основанием для переноса, - фреймо-слотовую структуру модели, оценку продуктивности и частности модели. Вариативность метафоры университета может иметь два ракурса рассмотрения:

- $\quad$ корреляция между изменениями глобальной и локальной политики в сфере образования и количеством метафор в соответствующем дискурсе;

- доминирование отдельных метафорических моделей в различные исторические периоды.

Применение второй методики позволило нам выявить наиболее распространенные модели смыслообразования, которые, с одной стороны, служат отражением того, как ученые видят данный феномен в контексте современной жизни общества, а с другой - формируют картину мира у рецепторов метафорических высказываний.

Неоспорим тот факт, что, находясь в рамках системы высшего образования, исследовательские университеты играют ключевую роль в подготовке специалистов высокого уровня, учёных и исследователей, а также в производстве новых знаний для поддержания инновационных систем многих стран. В этой связи метафора «башни из слоновой кости», «бархатной перчатки» для увековечивания власти элит, в терминах которых часто описывался не только средневековый университет, но и зачастую современный, метафора «разрушения и упадка» уступает место метафоре «созидания». Основываясь на анализе более 50 англоязычных публикаций последнего десятилетия, посвящённых проблемам высшего образования, мы выделили наиболее продуктивную исходную понятийную область, которая служит источником для многочисленных метафор. Условно её можно обозначить как «движущая сила»: 
The day of the university as an ivory tower pursuing knowledge for its own sake is drawing to a close, and the dawn of one in which it becomes a driver of regional and city economies beckons.

(Времена университета, выступающего в роли башни из слоновой кости, производящей знания для собственного блага, подходят к концу. Университет находится на заре того дня, когда он становится движущей силой регионального и городского развития [9] (перевод мой. - В.Н.).

Данные метафоры имеют положительную коннотацию, их сопровождают такие эпитеты, как important (важный), key (ключевой):

Regions with stake holder oriented strategy are often more open to seeing universities as important actors for regional development and allow them to delegate faculty and administrators to regional government boards (...видят университеты как важнное действующее лицо).

Key-drivers for sustainable development (Ключевая движущая сила устойчивого развития) [10] (перевод мой. - B.H.).

Университеты подталкивают общество на новые свершения, являются помощниками в экономической жизни, способствуют его устойчивому развитию:

Universities act as facilitators for sustainable development at the regional level.

Именно этот сектор должен приводить к повышению практической значимости результатов обучения и исследований, справедливости, экономичности и удовлетворенности студентов:

Higher education is not seen only as an engine for social and economic innovation but a sector that should innovate to improve learning outcomes, research outcomes, equity, cost efficiency, and student satisfaction [9].

Университеты, безусловно, выполняют или должны выполнять роль «посредника», находиться на переднем крае не только интеллектуального и научного развития, но и социальных изменений:

Higher education has been a principal medium for successive transformations: the civil rights movement, 1960s-1970s student power and grass-roots democracy, 1970s feminism, gay liberation, anti-nuclear and pro-ecology movements and the 1990s-2000s anti-globalisation protests against global injustice, power and violations of national sovereignty $[11]^{1}$.

Таким образом, университет и его функции переосмысливаются за счет использования существительных: medium (средство), driver (ведущий элемент двигателя), астог (действуюший субъект), engine (двигатель), facilitator (помощник), catalyst (катализатор) имеющих семантический компонент участия, движения, а также глаголов, характеризующих активное действие, стимул к движению, совершенствование: to innovate (npeобразовывать), to improve (улучшать), to delegate (делегировать), to trigger (запускать механизм), to mobilize (мобилизовать), to foster (взращивать). От современ-

${ }^{1}$ Высшие учебные заведения являются и являлись проводником социальных изменений. Вспомним движение за гражданские права, рост студенческой активности в 60-70-е гг. ХХ в. наряду с ростом демократического движения на местах, кампании против распространения ядерного оружия и в защиту экологии, а в 1990-2000-е выступления против глобализации, несправедливости, насилия сверхдержав и нарушения национального суверенитета (перевод мой. - B.H.). 
ного университета требуется, чтобы он выделялся на фоне остальных вузов своим уникальным видением и жизненной силой, был своего рода электростанцией, производящей интеллектуальную энергию. Понятийная сфера «электростанция» выступает как источник метафоры, а университет как цель метафорической экспансии:

Universities are society's premier knowledge-generating organizations (Университеты - это организации по выработке знаний) [12].

The university of San Diego is a powerhouse and economic engine... (Университет Сан-Диего - это энергетическая станция и экономический двигатель) [13].

Тем не менее некоторые отголоски университета как института, приносящего пользу только самому себе, ещё существуют. Бизнесу не всегда легко найти способы взаимодействия с научной базой университета. Понятийное пространство чего-то непостижимого и загадочного используется как источник метафоры, а университет как цель. Так, в приведённом ниже примере констатируется, что малым предприятиям очень трудно получить доступ к «чёрному ящику» университета. Напомним, что чёрный ящик - это термин, используемый для обозначения системы, внутреннее устройство и механизм работы которой очень сложны, неизвестны или неважны в рамках определённой задачи:

To help SMEs (the small and medium-sized enterprises) open the black box of higher education, different types of entry points have been created in the regions. One of the oldest is Knowledge House. Knowledge house offers soup-to - nuts service, stretching from the receipt and circulation of enquiries through project management and delivery to post-completion evaluation ${ }^{1}$ [9].

Университет завершает формирование личности, готовит её к гражданству, в рамках которого человек идентифицирует себя не только с семьёй или городом, но и с целой нацией и которое в более общем смысле формируется в интересах человечества. Большое количество метафор демонстрируют нам неразрывную связь университета и общества, помогают понять положение университета в сложной иерархии общественных отношений. Понятийная сфера «положение в пространстве» выступает источником второй по продуктивности метафорической модели, целью которой является университет:

In their role as regional institutions universities are embedded in regional networks. The embeddeness of regional institutions facilitates cooperation between regional stakeholders, which is an important element of social capital (...университеты встроены в региональную сеть. Именно эта включённость упрощуает сотрудничество между региональными стейкходлерами, которые являются важнейшим элементом сочиильного капитала).

Universities are embedded in communities, cities and nations and, in Europe, in a global region. (Университеты встроень в небольиие сообщества, города и страны, а в Европе ещё и в мировое пространство) [9].

\footnotetext{
1 Чтобы помочь бизнесу добраться до черного ящика высшего образования, в регионах реализуются различные программы взаимодействия. Научный домик-одна из тех программ, которая существует довольно давно. Она предполагает полное руководство проектом, начиная с получения запроса и заканчивая постпроектной оченкой результата (перевод мой. - В.Н.).
} 
Universities are nested within regional civilization... (вмонтированы в устройство локальной культуры...) [14].

Public higher education must be slotted into a landscape already occupied by established ways of imagining and practising higher education (Бесплатное высшее образование должно идеально вписаться в ландшафт уже существующего пазла...) [11].

Перед университетом остро стоит вопрос понимания своей миссии в распространении глобального общественного блага:

Research universities are integral parts of the global higher education and societal environтеnt (Исследовательские университеты являются неотъемлемой частью глобального выссшего образования и общества) [2].

Один из первых президентов знаменитого американского исследовательского университета Висконсин-Мэдисон провозгласил, что «граница университета - это граница государства» [2. С.108-109]. Это высказываниеметафора символизирует идеал служения обществу, а также принцип создания и распространения знаний:

Higher education has lost rationale and needs to re-ground itself in the social. It will need to find the way to make visible global public goods, if it is not to follow the monasteries into oblivion [11] $]^{1}$.

Universities are soaked in transmitting, studying and creating knowledge and part of a larger network of institutions (Университеты погружены в передачу, изучение и создание знаний и являются частью сети соииальных институтов) [11].

Глаголы to embed (внедряться), to slot (вставлять), to re-ground (обосноваться), to nest (встраиваться) указывают на местоположение в пространстве, помогают сориентироваться в системе ценностей. Некоторые из приведённых метафорических высказываний носят распространённый характер: например, когда сфера образования сравнивается с пазлом или ландшафтом. Использование глагола to soak (пропитывать, погружать) довольно необычно. Знания в данном контексте рассматриваются как текучая материя, а университет - как нечто способное её создавать, изучать и распространять.

Пространственная метафора позволяет понять и основное противоречие университетского устройства: локальность наряду с мобильностью, включение в жизнь местного сообщества наряду с функционированием на глобальном уровне:

Its founding antinomy (locality joined to mobility, embeddedness joined to universality) remains essential to it [9].

Неоспоримым является тот факт, что в университете производится большой объём новой информации, а также проводится исследовательская работа, результаты которой приводят к новым открытиям в различных областях. Базируясь в той или иной стране, университеты встроены в местную экономику и напрямую способствуют внедрению инноваций на локальном уровне. Для описания этих функций университет часто сравнивается с мостом, со-

${ }^{1}$ Высшие образовательные учреждения потеряли всякий смысл и должны вновь обрести своё место в социальном устройстве общества. Они должны найти способ создавать явные глобальные общественные блага, если не хотят вслед за монастырями кануть в небытие (перевод мой. - B.H.). 
единяющим различные социальные институты. Метафора функционирует благодаря использованию глагола to bridge (соединять мостом), прилагательного bridging (соединяюший), существительных а bridge (мост), a link (связующее звено). Источником метафорического употребления является понятийная сфера «строительство»:

Universities are important in bridging the gap between government and society. ...A bridging institution between academia and society (Роль университетов в налаживании связи между правительством и обществом чрезвычайна важна... Связующий элемент между учёными и обществом) [10] (перевод мой. - B.H.).

They provide the key link between global science and scholarship and a nation's scientific and knowledge system [2].

Занимая важное место в глобальной экономике знаний XXI в., университеты, наряду с локальными задачами осуществляют основную связь между национальными научными системами, мировой наукой и научным сообществом. В этом качестве они образно описываются как «two-way street» (улица с двусторонним движением) [2] или как часть огромной сети, охватывающей все мировое сообщество. В приведённом ниже примере метафора носит развёрнутый характер за счет использования существительного network (cemb), эпитета networked (объединённый сетью), глаголов to pattern (распределять по шаблону, моделировать), tо ехрапd (расширяться):

The third imaginary is the networked and potentially more egalitarian university world patterned by communications, collegiality, linkages, partnerships and global consortia. The network imaginary embodies permanent collaboration. It has an egalitarian, inclusive economic logic: as the network expands, each member receives ever increasing benefits, tending to global universality [11] .

Research universities are at the center of global knowledge communication and networks (Исследовательские университеть находятся в центре глобальной коммуникации и сообществ людей, распространяющих знания) [2].

Несмотря на сотрудничество и сетевое взаимодействие по вертикали и горизонтали, между университетами присутствует постоянная естественная конкуренция:

Networks can be annexed to competitive strategies. They are configured vertically as well as horizontally ('networking up'). Some are closed to broader connections and foster the interests of members on an exclusive basis. Universities are like sibling rivals, collaborating and competing with the same institutions... (...Университеты напоминают детей в семье, которые помогают друг другу, но в тоже время соперничают в рамках одного учреждения) [11] (перевод мой. - В.H.).

Как известно, конкуренция - неотъемлемая составляющая рыночных отношений, предпринимательства и производства, в рамках которых часто опи-

${ }^{1}$ Следующий образ - это взаимосвязанный и потенциально более равноправный мир университета, сформированный благодаря взаимодействию, коллегиальности, контактам, партнёрским отношениям и объединению учебных заведений. Образ сети или системы подразумевает постоянное сотрудничество. Он наделён инклюзивной, экономически выгодной для всех участников логикой: по мере того как сеть расширяется, каждый член получает растущие блага, стремясь к глобальному универсализму. 
сывается университет. Понятийные сферы «Рынок и предпринимательская деятельность» выступают как источник многочисленных метафор, целью которых являются различные аспекты университетской жизни.

The first imaginary is the idea of higher education as an economic market: education and research as products, higher education as national economic competition, universities as business firms, the WTO-GATS vision of a one-world free trade zone in learning andintellectual property. Higher education is seen as a system for producing and distributing economic values and for augmenting value created in other sectors $[11]^{1}$.

В этом контексте уникальным продуктом, который должен продавать университет, часто является он сам как некая целостность, которая пропагандирует интеграцию исследований и обучения. А его «предпринимательство» заключается в систематическом превращении социального капитала в общественное благо. Фуллер, перефразируя определение предпринимательства, данное Джозефом Шумпетером, заявляет, что университеты производят знание как общественное благо путем созидательного разрушения социального капитала [15. С. 31]. А историческую роль университета он видит как роль клапана предохранителя, позволяющего выпустить лишний пар. Хирш заявляет, что знание - это «позиционныци товар», чья ценность связана с относительным преимуществом, которое приобретают его обладатели. Таким образом, распространение знания может быть уподоблено валютной инфляции [15. С. 32]. Новая агрессивная эра экономики знаний, быстроменяющаяся политическая обстановка действительно заставляют университеты действовать подобно корпорациям: искусно планировать наём высококлассного профессорско-преподавательского состава, защищать свою уникальность, искать свою нишу в уже существующей системе высшего образования, грамотно распределять финансовые ресурсы. Однако чрезмерное использование метафор, связанных с предпринимательской деятельностью, может привести к неправильному восприятию университета как корпорации по производству лишь личного, а не общественного блага. По мнению Марджинсона, подобная опасная риторика привела к тому, что в 2010 г. правительство Великобритании отказалось финансировать гуманитарные и социальные науки:

Higher education institutions held in the public mind to be factories for producing private status goods and private knowledge goods come to focus largely on those functions alone. Increasingly, universities that come to see themselves as private firms catering for other private economic interests will embrace the producer/consumer mindset [11. C. 414] $]^{2}$.

${ }^{1}$ Первый образ представляет высшее образование в виде рынка: образование и исследовательская деятельность - это товары, высшее образование предстаёт в виде национального экономического соревнования, университеты - в виде компаний. Таково видение ВТО и ГАТС единого торгового образовательного пространства и интеллектуальной собственности. Высшее образование рассматривается как система, производящая и распределяющая экономические ценности и повышающая стоимость ценностей, произведённых в других сферах экономики. (перевод мой. B.H.).

2 Высшие учебные заведения, которые в глазах общественности ассоциировались с фабриками, производящими личные блага и знания частного характера, стали фокусироваться исключительно на этих функциях. В самом деле, университеты, которые позиционируют себя как частные компании, 
Рыночной метафоре очень близка по своей сути спортивная метафора. Обе имеют в своём концептуальном поле-источнике игроков, конкуренцию, противостояние:

Universities are key-players in both the individual as well as the social learning spheres (Университеты - ключевые игроки сличным зачётом и в соииальной сфере...) [10].

This is higher education as a field of status ranking and competition (Bblcmee образование представляет собой поле для определения статуса и конкуренции) [11. С. 421].

В настоящее время существует довольно много рейтингов, оценивающих высшие учебные заведения. Руководство стран и университетов используют инструмент рейтинга для того, чтобы позиционировать свои высшие учебные заведения на глобальном рынке образовательных услуг, а также как внутренние механизмы стимулирования. Именно рейтинги превращают исследовательские университеты в участников ожесточённой гонки. По словам Джамила Салми, бывшего координатора Всемирного банка по вопросам образования, «это марафон, а не спринт». Получение высокого рейтинга подразумевает инвестирование в исследования, что не может привести к мгновенным результатам. Естественно, что не все выдерживают эту гонку, да и немногие в научном сообществе уверены в том, что эта «гонка» ведётся по правилам. Чаще всего в выигрыше оказываются университеты, устроенные по англоамериканской или западноевропейской модели. Топ-100 не только стимулирует развитие национальной системы науки, но и подрывает её. Успеха добиваются немногие, а состояние беспокойства охватывает всех.

Now, global rankings have caught all universities, all over the world, in the same status-incentive trap. Status competition plays out not only between universities but between national systems. The neighbourhood becomes fairer in higher education when the main game is not winner take-all and, instead, is the production of shared and collective benefits [11. C. 429] $]^{1}$.

Критикуется подход к составлению рейтингов, где подсчитывается лишь количество публикаций, патентов на изобретения, грантов и библиотечных томов. Такой формальный метод оценки отбрасывает университеты назад, в «меркантильное прошлое»:

Current measures of academic achievements tend to be open-ended "Extensional magnitudes" that stress sheer numbers of publications, patents, students grant income, library volumes. Thus, we are back to academic bullionism [16].

В идеале все университеты стремятся к академическому совершенству, выбирая различные пути и стратегии для достижения своих целей. Понятийная сфера «путешествие» служит источником многих метафор, указывающих на то, что дороги эти разные и не всегда простые.

удовлетворяющие частные экономические потребности, полностью перенимают тип мышления «поставщик/потребитель» (перевод мой. - В.Н.).

${ }^{1}$ Глобальные рейтинги поймали все университеты в один и тот же капкан, дарующий им статус. Эти соревнования разыгрываются не только между университетами, но и между национальными системами образования. Общество выигрывает от соседства с университетом, если суть игры не в том, что победитель получает все, а в том, чтобы производить коллективные блага для всех (перевод мой. - B.H.). 
It may require a journey of internal reform for a university to take some responsibility for generating that prosperity (Может потребоваться путь внутренних трансформаций для того, чтобы университет взял на себя обязанность создания благосостояния) [9].

The entrepreneurial road to university self reliance (Предпринимательская дорога к университету, который может полагаться на свои силь) [17] (перевод мой. - B.H.).

The transformation of a university to match a new vision and new targets is a courageous endeavor. It also requires the political will to stay the course over the long term, bringing together "national policies, institutional capabilities, and knowledge integration” [18. C. 163]'.

Bblводbl

Индийский философ и учёный Рабиндранат Тагор сказал, что «выстее образование не просто даёт нам информацию, но приводит нашу жизнь $в$ гармонию со всем сущим» [19. C. XIV]. В данном выражении высшему образованию приписывается роль надёжного посредника, позволяющего человеку ориентироваться в системе ценностей и определять своё место в ней. Анализ ведущих когнитивных метафорических моделей дискурса, посвящённого проблемам университета, позволил наглядно продемонстрировать то, как переосмысливается роль высшего образования в современном контексте. Университет выступает в качестве движущей силь общества, подталкивает его на новые свершения, является помошником в экономической жизни, локальной и глобальной сетью, мостом, осуществляюшим связь на всех уровнях, гарантом устойчивого развития. Перед университетами современности стоит много трудноразрешимых задач: преодоление разрыва между гуманитарной, естественно-научной и деловой культурами, нахождение на переднем крае интеллектуального и научного развития, улучшение понимания человеческой природы посредством развития социальных и гуманитарных наук, сочетание серьёзной научной подготовки и глубоких гуманистических убеждений. С помощью метафор высвечиваются и проблемные зонь университета, такие как сохраняющаяся закрытость университета, недостаточная гибкость, излишняя коммерцииализация, погоня за формальными показателями.

Сейчас, когда в России идет реформирование образования, когда выстраивается определённая "архитектура» высшего образования и стоит задача завоевания международного рынка образовательных услуг, понимание существующих проблем очень важно. Безусловно, конкурсные механизмы поддержки программ развития вузов и их инициатив, запущченные государством, стимулируют переосмысление места российских университетов среди других университетов страны и мира. Хорошим подспорьем может стать и изучение опыта зарубежных исследовательских университетов, чьи достижения и просчёты переосмысливаются посредством приведённых

1 Преобразование университета, ведущее к новому видению и новым целям, является смелым предприятием. Для его реализации требуется политическая воля следовать выбранным курсом, объединяя национальные стратегии, институциональные возможности и накопленные знания. (перевод мой. - B.H.). 
выше метафор. Критический анализ позволит не только избежать ошибок, но даст толчок к порождению новых смыслов, новым шагам в трансформации и развитии университетов как образовательного пространства.

\section{Лumepamypa}

1. Fallon D. The German University: A Heroic Ideal in Conflict with the Modern World. Boulder: Colorado Associated University Press. 1980. 72 p.

2. Altbach Ph. G. The past, present and future of the research university // The road to academic excellence: the making of world-class research universities/ edited by Philip G. Altbach and Jamil Salmi. World Bank. 2011. P. 11-29.

3. Ортега-и-Гассет Х. Две великие метафоры // Теория метафоры. М., 1990. С. 68-81.

4. Арутюнова Н.Д. Метафора и дискурс // Теория метафоры. М.: Прогресс, 1990. С. 5-32.

5. Демьянков В.З., Кубрякова Е.С. Когнитивная лингвистика // Краткий словарь когнитивных терминов. М., 1996. С. 53-55.

6. Лакофф Дж., Джонсон М. Метафоры, которыми мы живем // Теория метафоры. М., 1990. C. $387-415$.

7. Харнард С. Философы о метафоре. URL: http://www.metaphor.narod.ru/ revew/ phil revew.htm

8. Чудинов А.П. Россия в метафорическом зеркале: когнитивное исследование политической метафоры (1991-2000). Екатеринбург, 2001. 238 с.

9. Ischinger B., Puukka J. Universities for Cities and Regions: Lessons From the OECD Reviews. Change. 2009. P. 8-13.

10. Sedlacek $S$. The role of universities in fostering sustainable development at the regional level // Journal of Cleaner Production. No. 48. 2013. P. 74-84.

11. Marginson S. Higher Education and Public Good. University of MHigher Education Quarterly. Vol. 65, No. 4, October 2011. P. 411-433.

12. Lowe Gr.S. Universities as Healthy Work Environments. URL: http://www. grahamlowe.ca/ documents/138/Healthy\%20Universities.pdf.

13. URL:http://eap.ucop.edu/Documents/ReciprocalExchanges/SpotlightUCSD.pdf

14. Postiliogne G.A. The rise of research universities: the Hong Kong University of Science and Technology // The road to academic excellence: the making of world-class research universities/ edited by Philip G. Altbach and Jamil Salmi. World Bank. 2011. P. 63-101.

15. Fuller $S$. What makes universities unique? Updating the ideal for an entrepreneurial age. Higher education management and policy. 2005. Vol. 17. No 3. P. 27-51

16. Fuller $S$. The governance of science in an age of Knowledge Management. URL: http://docs.lib.purdue.edu/cgi/viewcontent.cgi?article=1528HYPERLINK "http://docs.lib.purdue.edu/ cgi/viewcontent.cgi?article=1528\&context=iatul"\&HYPERLINK "http://docs.lib.purdue.edu/ cgi/ viewcontent. cgi? article $=1528 \&$ context $=$ iatul"context $=$ iatul

17. Clark B. R. Sustaining Change in Universities: Continuities in Case Studies and Concepts. The Journal of Higher Education. 2006. Vol. 77. No. 5. P. 932-934.

18. Mukherjee H., Poh Kam Wong. The National University of Singapore and the University of Malaya: Common Roots and Different Paths // The road to academic excellence: the making of worldclass research universities/ edited by Philip G. Altbach and Jamil Salmi. World Bank. 2011. P. 129167.

19. The road to academic excellence: the making of world-class research universities/ edited by Philip G. Altbach and Jamil Salmi. World Bank. 2011. P. XIV.

\section{RETHINKING UNIVERSITY THROUGH THE PRISM OF METAPHOR}

Tomsk State University Journal of Philology, 2016, 1(39), pp. 22-34. DOI: 10.17223/19986645/39/3

Novikova Vera P., Chelyabinsk State Pedagogical University (Chelyabinsk, Russian Federation).

E-mail: veranovik@mail.ru

Keywords: cognitive linguistics, language metaphor, metaphorical model, tertiary education, research university. 
Modern tertiary education has to face such realities as massification of enrollement, the ongrowing role of private sector, the rise of Asian countries as academic centers, the changing nature of the universities' functional goals, physical and logistical structure. Global knowledge economy of the 21 st century relies heavily on research universities which serve as flagships for post-secondary education worldwide. Within this framework there are a lot of challenges to solve for a research university: to bridge the gaps dividing scientific, humanitarian and business cultures, to operate at the cutting edge of intellectual and scientific development, to contribute to better understanding of human nature through social sciences and humanities, to combine profound scientific background and humanitarian beliefs. Being situated in this or that country, universities are embedded in local economy, contributing to innovation advancement on a local level. However, the role of the university as global goods disseminator is of great importance. Undoubtedly, peoples' aspirations for the future are connected with universities worldwide. Being aware of this mission, prominent thinkers and scholars within the world of academia try to reflect on the role of a modern university, assess its activity and show new pathways to progress and development. On the basis of fifty publications of the recent decade, dedicated to the problems of tertiary education, the author discerned and described metaphorical models contributing to meaning formation. Though research universities have their distinctive national features, quite similar images are used to portray them: they are presented as a driving force, a bridge, a powerhouse necessary to change the society and man; a market, a corporation, a factory, a participant of competition, hunting and race, satisfying the needs of the demanding consumers. On the one hand, the array of diverse metaphors reflects how the authors perceive the functions of a research university within the modern society, on the other hand, they form deeply rooted stereotypes in readers who serve as recipients of these metaphors. Though the general perception of the role of universities is rather positive, metaphors help to highlight and analyze their problem zones: universities' isolation, bullionism, unclear vision of one's mission. Being a powerful mechanism of meaning generation, metaphors can help to compartmentalize the existing challenges universities face and set the tone for their future development.

\section{References}

1. Fallon, D. (1980). The German University: A Heroic Ideal in Conflict with the Modern World. Boulder: Colorado Associated University Press.

2. Altbach, Ph.G. (2011) The past, present and future of the research university. In: Altbach, Ph.G. \& Salmi, J. (eds) The road to academic excellence: the making of world-class research universities. World Bank.

3. Ortega y Gasset, J. (1990) Dve velikie metafory [Two great metaphors]. In: Arutyunova, N.D. (ed.) Teorija metafory [Theory of metaphor]. Moscow: Progress.

4. Arutyunova, N.D. (1990) Metafora i diskurs [Metaphor and discourse]. In: Arutyunova, N.D. (ed.) Teorija metafory [Theory of metaphor]. Moscow: Progress.

5. Dem'yankov, V.Z. \& Kubryakova, E.S. (1996) Kognitivnaja lingvistika [Cognitive linguistics]. In: Kubryakova, E.S. (ed.) Kratkijj slovar' kognitivnykh terminov [Conscise dictionary of cognitive terminology]. Moscow: Moscow State University Faculty of Philology.

6. Lakoff, J. \& Johnson, M. (2004) Metafory, kotorymi my zhivem [Metaphors we live by]. In: Arutyunova, N.D. (ed.) Teorija metafory [Theory of metaphor]. Moscow: Progress.

7. Harnard, S. (n.d.) Filosofy o metafore [Philosophers about metaphor]. [Online]. Available from: http://www.metaphor.narod.ru/revew/phil_revew.htm.

8. Chudinov, A.P. (2001) Rossiya v metaforicheskom zerkale: kognitivnoe issledovanie politicheskoy metafory [Russia in metaphorical mirror: the research of a political metaphor (19912000)]. Ekaterinburg: Ural State Pedagogical Univeristy.

9. Ischinger, B. \& Puukka, J.(2009) Universities for Cities and Regions: Lessons From the OECD Reviews. Change.

10. Sedlacek, S. (2013) The role of universities in fostering sustainable development at the regional level. Journal of Cleaner Production. 48. pp. 74-84.

11. Marginson, S. (2011) Higher Education and Public Good. Higher Education Quarterly. 65:4. pp 411-433. DOI: $10.1111 / \mathrm{j} .1468-2273.2011 .00496 . x$

12. Lowe, G.S. (2005) Universities as Healthy Work Environments. [Online]. Available from: http://www.grahamlowe.ca/documents/138/Healthy\%20Universities.pdf.

13. UC San Diego. (2016) Spotlight UCSD. [Online]. Available from: http://eap.ucop.edu/ Documents/ReciprocalExchanges/SpotlightUCSD.pdf. 
14. Postiliogne, G.A.(2011) The rise of research universities: the Hong Kong University of Science and Technology. In: Altbach, Ph.G. \& Salmi, J. (eds) The road to academic excellence: the making of world-class research universities. World Bank.

15. Fuller, S. (2005) What makes universities unique? Updating the ideal for an entrepreneurial age. Higher Education Management and Policy. 17:3. pp. 27-51.

16. Fuller, S. (2001) The governance of science in an age of Knowledge Management. [Online]. Available at: http://docs.lib.purdue.edu/cgi/viewcontent.cgi?article=1528\&context=iatul.

17. Clark, B. (2006) Sustaining Change in Universities: Continuities in Case Studies and Concepts. The Journal of Higher Education. 77:5. pp. 932-934.

18. Mukherjee, H. \& Poh Kam Wong. (2011) The National University of Singapore and the University of Malaya: Common Roots and Different Paths. In: Altbach, Ph.G. \& Salmi, J. (eds) The road to academic excellence: the making of world-class research universities. World Bank.

19. Altbach, Ph.G. \& Salmi, J. (eds) (2011) The road to academic excellence: the making of world-class research universities. World Bank. 